\title{
The tree-lined path to carbon neutrality
}

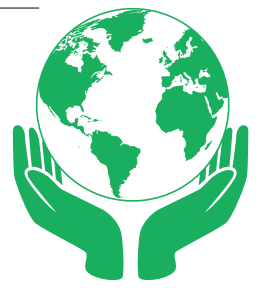

\author{
Asryelle Mora Rollo, Audrey Rollo and Camilo Mora
}

The Carbon Neutrality Challenge is an initiative to mitigate climate change, in which individuals estimate their $\mathrm{CO}_{2}$ footprint and then plant enough trees to offset it. Thousands of trees have been planted by volunteers in Hawaii who took the Carbon Neutrality Challenge.

Even with a full implementation of the Paris Agreement, maintaining global warming below $2{ }^{\circ} \mathrm{C}$ before 2100 might not be attained. Thus, averting the threat of climate change will require some degree of luck in discovering new technologies, or a considerable improvement of existing methods that reduce and/or capture carbon emissions. Planting trees for carbon offset, as an example, sounds simple, but this approach faces numerous technical problems for it to be successful at globally-relevant scales.

In 2014, the Carbon Neutrality Challenge was started to help people become carbon neutral through tree planting. A simple web application allows individuals to estimate their own carbon emissions and select from a diversity of native species the trees that can be planted to offset those emissions. Early on, we carried out tens of events planting 100 trees at a time with 20 people at most. In our last event, we planted 10,000 trees with 2,000 volunteers in two hours. We hope to plant 100,000 trees at once in the next phase of the project, and ultimately, our ambition is to plant 1 million trees a year in Hawaii, which will offset all the carbon emissions of the state.

Our approach to facilitate the successful implementation of large-scale plantings has been one of incremental learning, fixing limitations revealed by smaller events in order to increase the success of larger plantings. In our 'scaling-up learning', we have increased tree survival considerably by developing new methods for mass propagation of native species suited for specific environments, creating several irrigation and water catchments and

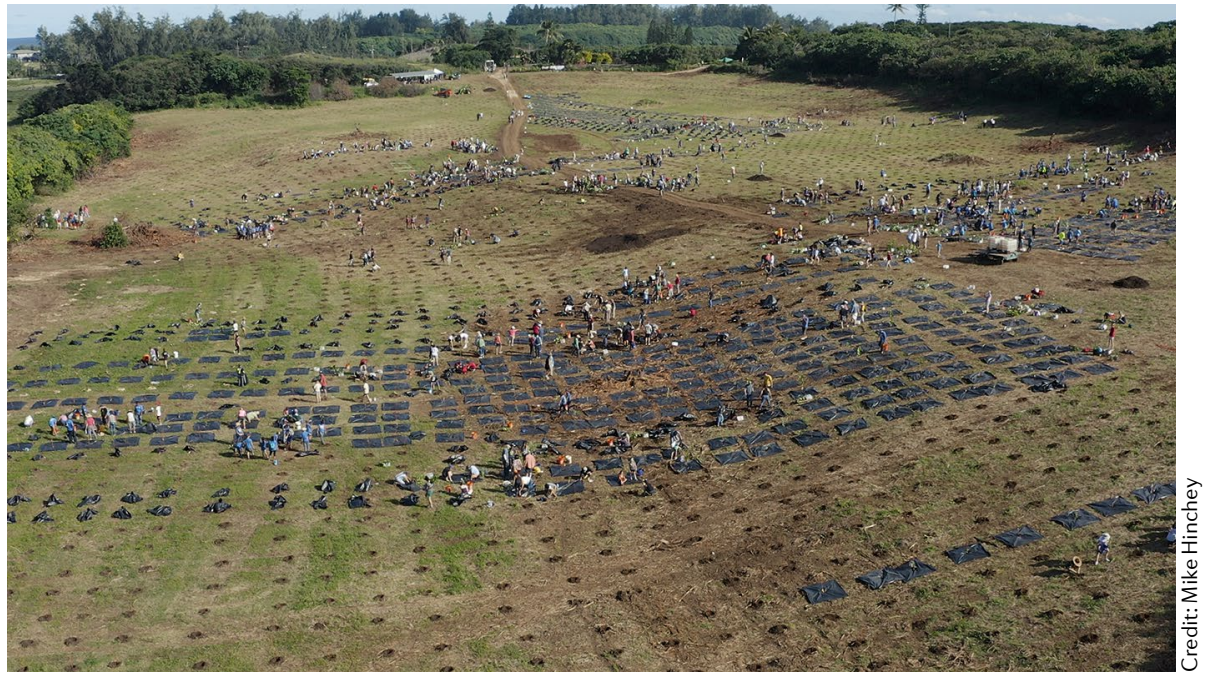

testing numerous approaches for weed control. Recently, we added new functionality to our webpage to rank teams of participants by their number of trees planted, which has increased user participations while also easing the coordination of events with large numbers of people.

In Hawaii, we could plant 1 million trees a year for 40 years before we ran out of space. For the rest of the world, there are over 2 billion acres of land that could be planted without conflicts with urban development or farming. If this planting is achieved, up to $75 \%$ of the anthropogenic carbon emissions so far could be offset; no other available technology even comes close. This scale of restoration might appear daunting, but it equates to just $\sim 130$ trees per person, or a 10 -hour job for an average individual! The massive public participation in large planting events in India, Pakistan, Ethiopia and Bhutan highlights the eagerness of people to engage worldwide. Fixing climate change becomes that much simpler if we all take on the Carbon Neutrality Challenge and start planting trees now.

Asryelle Mora Rollo', Audrey Rollo ${ }^{1}$ and Camilo Mora ${ }^{1,2}$ 网 2University of Hawai'i at Mānoa, Honolulu, HI, USA. 凶e-mail:cmora@hawaii.edu

https://doi.org/10.1038/s43017-020-0069-3

Competing interests

The authors declare no competing interests.

\section{RELATED LINKS}

Carbon Neutrality Challenge: http:// www.GoCarbonNeutral.org
${ }^{\prime}$ Carbon Neutrality Challenge, Honolulu, HI, USA. 